\title{
On the Explanatory Power of the Hypothesis of Semantic Determination to Causative Alternation
}

\author{
Qian $\operatorname{Liu}^{1 \& 2}$ \\ ${ }^{1}$ School of Foreign Languages, Linyi University, Linyi, Shandong, China \\ ${ }^{2}$ Department of English and Literature, The University of Suwon, Wau-ri, Bongdam-eup, Hwaseong-si, \\ Gyeonggi-do 445-743, Korea \\ Correspondence: Qian Liu, School of Foreign Languages, Linyi University, Shuangling Road, Linyi, Shandong \\ 276005, China. E-mail: liuqian@1yu.edu.cn
}

Received: March 7, 2020 Accepted: April 10, 2020 Online Published: April 15, 2020

doi:10.5539/ijel.v10n3p241 URL: https://doi.org/10.5539/ijel.v10n3p241

The research is financed by Linyi University, No. HX10202 (Sponsoring information).

\begin{abstract}
According to the hypothesis of semantic determination, meaning is a key to verb behavior; verb fall into classes on the basis of shared components of meaning, and members in the same semantic class may share patterns of behavior. This paper aims to verify the validity of component analysis in predicting syntactic behavior. It first makes a brief introduction to causative alternation, then compares the meaning components and usage of three verbs, i.e., break, cut and bake. Finally, two contradictions are found in the alternation analysis of these verbs. Therefore, the component analysis cannot completely predict their alternation type. Consequently, the explanatory power of this hypothesis is very limited as far as causative alternation is concerned.
\end{abstract}

Keywords: semantic determination; component analysis; causative alternation

\section{Introduction}

Bloomfield (1933) once wrote that "The lexicon is really an appendix of the grammar, a list of basic irregularities". Nevertheless, Levin (1993) refutes this opinion, asserting that meaning is a key to verb behavior; verb fall into classes on the basis of shared components of meaning, and members in the same semantic class may share patterns of behavior. This is the controversial hypothesis that syntactic properties are semantically determined, whose validity remains to be verified.

Meanwhile, the causative alternation has always been a headache for Chinese English learners. For instance, break is a high frequency verb participating in causative alternation; even so, the experiments of Tang (2010) and Mo (2016) reveal that many subjects deny its anticausative variant though they are very familiar with its causative counterpart. Mo (2016) analyzes this phenomenon in detail, pointing out that lexical meaning and relative frequency might be the two main causes of their misconception. According to his explanation, the meaning of break indicates the existence of an external causer and thus Chinese learners tend to regard it as a transitive verb. In addition, in spite of the high appearance frequency in textbooks, its usage as intransitive verb is relatively much less common. Consequently, the interaction of the two elements above makes them skeptical of its grammaticality as an intransitive verb. Though his analysis is reasonable and convincing empirically, the justification of the anticausative variant has been left uncovered. Even if its input frequency rises in course books, the learners may still be confused about the intransitive use due to the supposed existence of an external causer. In fact, many English teachers also feel inadequate in this syntactic pattern, i.e., the anticausative variant of break. In addition, which verbs allow causative alternation and which verbs do not? In recent years, linguists (Dowty, 2001; Coppock, 2008; Levin, 2011) make unremitting efforts so as to seek rules that govern the alternation. Among them, Levin (1993) identifies the meaning components of different types of verbs to justify their participation in various alternations. Once verified, there must be great enlightenment to our teaching and learning of causative alternation, which may further deepen our understanding of the nature of language as well.

Therefore, the present article attempts to examine the reliability of Levin's study. It first makes a brief introduction to causative alternation, and then reviews the usage of break, comparing its meaning component and 
alternation types with two other verbs cut and bake. Finally, the validity of her hypothesis that syntactic properties are semantically determined is challenged due to the contradictory arguments found in her analysis.

\section{Brief Introduction to Causative Alternation}

Causative alternation refers to the cross-linguistic phenomenon that certain verbs (change of state/change of degree) can be used transitively or intransitively. As is mentioned above, break is a verb of causative alternation.

(1) a. Transitive Use: He broke the vase. [Causative]

b. Intransitive Use: The vase broke. [Anticausative/inchoative]

In (1a), the transitive use of the verb is named causative because it is the subject (He) that causes the change of state (the vase broke), while the intransitive use in (1b) is called anticausative or inchoative for it only describes the change that the participant undergoes (the vase broke), omitting the role of the subject. The statement above justifies the designation of the term "causative alternation", whose variants might be generalized as follows:

(2) a. Causative: agent + verb-transitive + patient

b. Anticausative: Patient + verb-intransitive

That is to say, in (1a), the external argument ("He") corresponds to the theta role of agent, and its object (the vase), the thematic role of patient, as is shown in (2a); the patient alternatively serves as the subject of the anticausative variant in (2b). Obviously, the structures above suggest the interaction between syntactic behaviors and lexical meanings.

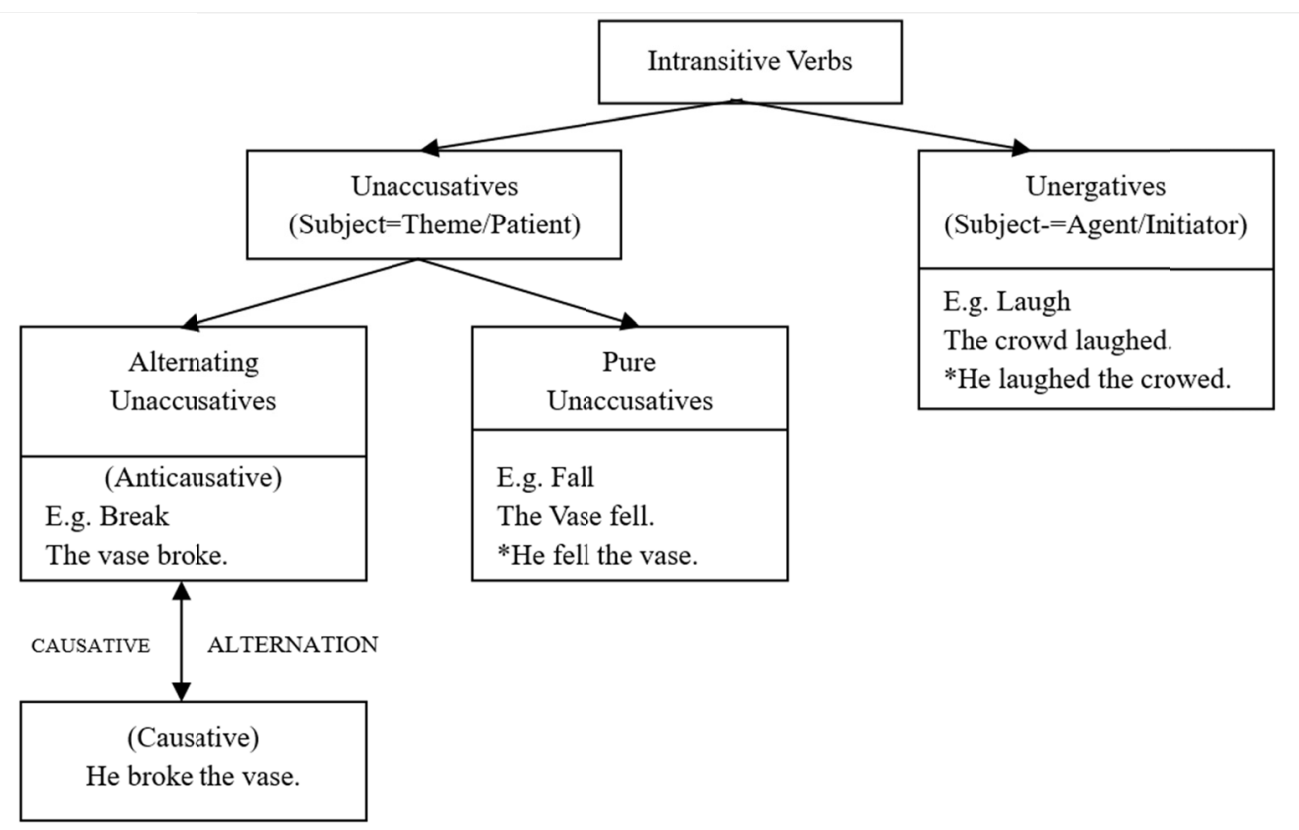

Figure 1. The unaccusative hypothesis

The Unaccusative Hypothesis, proposed by Pelmutter (1978) and elaborated by Burzio (1986), points out that the subject of unaccusative verb (intransive) is the underlying object, while that of the unergative verb (intransitive) is the underlying subject. It is the first theory about syntactic configurations concerning intransitive verbs, whose idea might be represented by the figure above (Figure 1), based on information discussed in Schäfer (2009). The flow figure helps to further clarify our understanding of the causative alternation, illustrating the differentiation of alternating verbs from the other categories of intransitive verbs. In addition, it also "provides a context for debating whether syntactic behavior is semantically determined" (Levin, 1993). In the following section, the meaning components of some verbs and their usage are reviewed to probe the interaction between syntactic patterns and lexical meanings. 


\section{A Comparison of Usage Between Break, Cut and Bake}

\subsection{The Usage of Break}

First, let's go back to break and scrutinize its usage as a verb of causative alternation. Example (1) is repeated here as (3).

(3) a. He broke the vase.

b. The vase broke.

As is mentioned in the very beginning of this paper, many Chinese students do not consider (3b) to be grammatical. Instead, its passive voice counterpart, that is, "The vase was broken", is more acceptable due to the supposed existence of an agent. In fact, break is usually classified to the type of verbs showing change of state. Its two variants may be formulated as follows:

(4) a. X (= agent) acts on Y (patient), causing Y (= patient) to go to a state.

b. $\mathrm{Y}(=$ patient $)$ goes to a state.

Therefore, (3b) corresponds to (4b), simply emphasizing the result and omitting the agent. In effect, causative alternation is cross-linguistic and not limited to English. The same alternation may be found in Chinese as well:

(5) a. 他打碎了花瓶。 He broke the Vase.

b. 花瓶（打）碎了。 The vase broke.

Having been told that break may denote a change of state without an addition of the notion of causer, the learners may accept the anticausative variant easily with the hint from Chinese. Certainly, there are many other cross-linguistic examples in English and Chinese and open is another verb of causative alternation.

(6) a. He opens the door. 他开了门。

b. The door opens. 门开了。

Up to now, the learners might have the impression that verbs denoting change of state like break and open may participate in causative alternation, that is, they might be used transitively and intransitively as well. The issue of causative alternation, as is mentioned in Kang (2010), may be easier for learners to understand.

\subsection{A Comparative Study of Cut and Break}

However, as Coppock (2008) points out, the causative alternation is very complex, which includes putative exceptions. Now let's examine the use of $c u t$, which might be an arbitrary exception to transitive alternation.

(7) a. Mary cut the bread.

b. * The bread cut.

Obviously, cut is a resultative verb as break; both words have the same meaning component [+ cause of change], hence they are supposed to share the same syntactic pattern. Nevertheless, different from break, cut cannot participate in causative alternation. In addition, they also differ with respect to some other diathesis alternations, as is shown by examples in (8).

(8) a. Mary cut at the bread.

b. *He broke at the vase.

c. Mary cut Bill on the arm.

d. *He broke Bill on the arm.

That is, cut may appear in conative alternation (8a) and the body-part possessor ascension alternation (8c), whereas break displays neither of the two tendencies. Undoubtedly, both of them can be used as transitive verbs, connecting two arguments as their subject and object respectively. In addition, they can be applied in middle constructions as well. These two similarities are exemplified in (9).

(9) a. Mary cut the bread.

b. He broke the vase.

c. The bread cuts easily.

d. The vase breaks easily.

In view of the analyses above, the distinct syntactic patterns of break and cut may be summarized in the following table. 
Table 1. The alternation types of break and cut

\begin{tabular}{|c|c|c|c|c|}
\hline verb Alternation & causative & conative & Body-part possessor ascension & middle \\
\hline break & $\sqrt{ }$ & $\mathrm{X}$ & $\mathrm{X}$ & $\sqrt{ }$ \\
\hline cut & $X$ & $\sqrt{ }$ & $\sqrt{ }$ & $\sqrt{ }$ \\
\hline
\end{tabular}

Here the question is which factors lead to their divergent use in the diathesis alternations above. In effect, the reason just lies in the fact that the two verbs are different in their meaning components (Levin, 1993, p. 9). In spite of their common meaning [ + change of state], cut also has two other components [+ motion] and [+ contact] in its meaning; the combination of these two components explains its application in conative alternation (9a) and the latter, body-part possessor ascension alternation $(9 \mathrm{c})$. Because $c u t$ has its meaning components as $[+$ change of state] [+ motion] [+ contact], it cannot be a verb of causative alternation, which must be pure change of state verb as break. In contrast, due to its lack of components [+ motion] and [+ contact], break have neither conative alternation (8b) nor body-part possessor ascension alternation (8d). As to the middle alternation, it is also manifested by verbs of change of state, thus both break and cut are grammatical.

Meanwhile, Levin (1993) claims that the behavior patterns of break and cut should arouse our attention for they represent two types of verb respectively, whose members have the same syntactic properties due to their common meaning components.

Table 2. Break-type verbs and cut-type verbs

\begin{tabular}{lllllll}
\hline $\begin{array}{llll}\text { Break verbs } \\
\text { Cut verbs }\end{array}$ & break & crack & rip & shatter & snap & $\ldots$ \\
\hline cut & hack & saw & scratch & slash & $\ldots$ \\
\hline
\end{tabular}

So far, the analyses above seem to justify Levin's claim and a tentative conclusion might be reached that verbs of causative alternation are supposed to have the pure meaning component [ + change of state]. If it is the case, the burden of mastering this syntactic pattern will be eased to some extent, for there is only one problem left to be solved, that is, which verbs fall into this range of meaning. However, the feasibility of this conclusion still needs to be verified under a larger context.

\subsection{A Comparative Study of Bake and Break}

According to Atkins, Kegl and Levin (1988), “cooking verbs show an unexpected set of properties". Since bake is a verb of this type, its syntactic behavior will be examined to test the applicability of the tentative conclusion above.

(10) a. He baked cake at $375 \mathrm{~F}$.

b. The cake baked at $375 \mathrm{~F}$.

The examples in (10) prove that bake is a verb of causative alternation, so it must have the pure meaning component [ + change of state] as break. However, this analysis does not seem to work in the following examples.

(11) a. He bakes cake on Tuesdays./He bakes on Tuesdays.

b. He broke the vase. $/ *$ He breaks on Tuesdays.

c. He baked a cake for Chris./He baked Chris a cake.

d. He broke the vase for me. $/ *$ He broke me the vase.

Virtually, bake may participate in the unspecified object alternation (11a) and benefactive alternation (11c), while break cannot appear in both constructions. The problem is summarized in the following table. 
Table 3.The alternation types of bake and break

\begin{tabular}{lccc}
\hline alternation & verb & bake & break \\
\hline Causative alternation & & \\
Unspecified object alternation & $\sqrt{ }$ & $\sqrt{ }$ \\
Benefactive alternation & $\sqrt{ }$ & $X$ \\
\hline
\end{tabular}

Source: Atkins, kegl, and Levin, 1988.

That is to say, bake must have meaning components other than [+ change of state] due to its application in (11a) and (11c). Consequently, the component [+ activity of creation] is identified by Atkins, kegl and Levin (1988) and the difference between the two components is explained as follows:

CHANGE OF STATE bake: to change the state of something by dry heat in an oven.

ACTIVITY OF CREATION bake: to create by means of changing the state of something by dry heat in an oven.

Accordingly, the change of state bake explains the grammaticality of the causative alternation in example (10), while the activity of creation bake justifies its application in the latter two alternations (11a) and (11c). With the identification of its new component, the application of bake in Table 3 is updated in Table 4.

Table 4. The alternation types of bake (change of state), bake (activity of creation) and break

Source: Atkins, kegl, and Levin, 1988.

\begin{tabular}{llll}
\hline \multirow{2}{*}{ alternation } & $\begin{array}{l}\text { bake } \\
\text { (change) }\end{array}$ & $\begin{array}{l}\text { bake } \\
\text { (create) }\end{array}$ & break \\
\hline Causative alternation & $\sqrt{ }$ & $\mathrm{X}$ & $\sqrt{ }$ \\
Unspecified object alternation & $\mathrm{X}$ & $\sqrt{ }$ & $\mathrm{X}$ \\
Benefactive alternation & $\mathrm{X}$ & $\sqrt{ }$ & $\mathrm{X}$ \\
\hline
\end{tabular}

Finally, the two senses of bake offer reasonable explanation to its different usage with break. Based on this solution, Levin posits polysemy and multiple class membership for 784 of 3024 verbs (26\%), according to Lapata and Brew (2004). However, if it is the case, why can't cut be applied in the causative alternation since one of its meaning components is just [+ change of state] as bake. Furthermore, if the difference between cut and break is that the latter is a pure change of state verb and thus may appear in causative alternation, then bake cannot be a verb of causative alternation, for it is not a pure change of state verb with its two senses. These are the two contradictions of Levin's analyses on the usage of break, cut, and bake in different alternations.

\section{Conclusion}

Rosen (1984) states that meaning alone is not predictive of word class membership. Levin (1993) refutes his opinion, emphasizing the importance of the appropriate identification of meaning components. She recommends the technique of diathesis alternation to pin down the meaning components of words. Lakeoff (1987) and Taylor (1989) deny the absolute objectivity of this kind of analysis, positing that the identification of prototype involves human cognition and thus has individual difference. They further point out that the methodology of meaning component, though it appears to be scientific and objective, will be hindered in its application due to its ignorance of our subjective cognition, the language context, social belief, cultural difference, and so on.

In this paper, the usage of three verbs, i.e., break, cut and bake are compared so as to verify the validity of component analysis. Undoubtedly, Levin's above study is rewarding, providing insights into the nature of lexical meanings. It might, to a certain degree, summarize the semantic and syntactic properties of a small range of words, for instance, the break type in Figure 2. However, it turns out that her arguments are contradictory in the larger context and the meaning component cannot completely predict the alternation type of the above verbs. In other words, due to the inadequacy of component analysis, the hypothesis of semantic determination has not yet been proved to be true. Consequently, its explanatory power is very limited as far as causative alternation is concerned.

However, the hypothesis of semantic determination still cannot be completely negated due to the deviation of research methodology. As is noted by Levin (1993), "no one is likely to deny that words with similar meaning show at least some tendency toward displaying the same syntactic behavior". Therefore, it is still a rather arduous task to verify the validity of relevant researches in this field (Dowty, 1999; Coppock, 2008; Levin 2011). Predictably, with the enrichment of our knowledge about causative alternation, its semantic and syntactic 
interaction will be further understood one day.

\section{References}

Atkins, B., Kegl, J., \& Levin, B. (1988). Anatomy of a verb entry. International Journal of Lexicography, 1, 84-126. https://doi.org/10.1093/ijl/1.2.84

Bloomfield, L. (1933). Language. New York: Holt, Rinehart and Winston.

Burzio, L. (1986). Italian syntax: A Government-Binding approach. Dordrecht: Reidel. https://doi.org/10.1007/978-94-009-4522-7

Coppock, E. (2008). The logical and empirical foundations of Baker's paradox. Stanford, CA: Stanford University dissertation.

Dowty, D. (2001). The semantic asymmetry of 'argument alternations' (and why it matters). In v. d. M. Geart \& G. B. t. M. Alice (Eds.), Groninger Arbeiten zur germanistischen Linguistik Nr. 44. Groningen: Center for Language and Cognition.

Kang, X. (2010). On the L2 acquisition of English causative alternation: The role of verb semantics and entrenchment. Foreign Language Teaching and Research, 6(42), 431-437.

Lakeoff, G. (1987). Women, Fire, and Dangerous Things: What Categories Reveal about the Mind. Chicago: The University of Chicago Press. https://doi.org/10.7208/chicago/9780226471013.001.0001

Lapata, M., \& Chris, B. (2004). Verb class disambiguation using informative priors. Computational Linguistics, 30(1), 45-73. https://doi.org/10.1162/089120104773633385

Levin, B. (1993). English verb classes and alternations. Chicago: University of Chicago Press.

Levin, B. (2011). Mobilising research knowledge in education. London Review of Education, 9(1), 15-26. https://doi.org/10.1080/14748460.2011.550431

Mo, J. (2016). A study of the differences between Chinese learners' acquisition of English transformable Unaccusative Verbs. Journal of Xi'an Foreign Languages University, 3(24), 65-71.

Pelmutter, D. M. (1978). Impersonal passives and the unaccusative hypothesis. Berkeley Linguistics Society, 4, 157-189. https://doi.org/10.3765/bls.v4i0.2198

Rosen, C. (1984). The interface between semantic roles and initial grammatical relations. In M. P. David \& R. Carol (Eds.), Studies in Relational Grammar 2 (pp. 38-80). Chicago: University of Chicago Press.

Schäfer, M. (2009). Geschichte des Bürgertums. Eine Einführung: Köln-Weimar-Wien.

Taylor, J. R. (1995) Linguistic Categorization: Prototypes in Linguistic Theory. Oxford: Oxford University Press.

\section{Copyrights}

Copyright for this article is retained by the author, with first publication rights granted to the journal.

This is an open-access article distributed under the terms and conditions of the Creative Commons Attribution license (http://creativecommons.org/licenses/by/4.0/). 